\title{
Gross osteomorphometrical study of ossa coxarum of the leopard (Panthera pardus)
}

\author{
D. N. Podhade ${ }^{1}$, A. B. Shrivastav ${ }^{1}$ and Rakhi Vaish ${ }^{2}$ \\ 1. Centre for Wildlife Forensic and Health, Nanaji Deshmukh Veterinary Science University, \\ South Civil lines, Jabalpur, Madhya Pradesh, India; \\ 2. Department of Veterinary Anatomy and Histology, College of Veterinary Science and Animal Husbandry, Nanaji \\ Deshmukh Veterinary Science University, J abalpur, Madhya Pradesh, India \\ Corresponding author: D. N. Podhade, email: drdevendrapodhade@rediffmail.com \\ Received: 20-10-2013, Revised: 02-12-2013, Accepted:05-12-2013, Published online: 08-01-2014
}

doi: 10.14202/vetworld.2014.10-12

How to cite this article: Podhade DN, Shrivastav AB and Vaish R (2014) Gross osteomorphometrical study of ossa coxarum of the leopard (Panthera pardus), Veterinary World 7(1): 10-12.

\begin{abstract}
Aim: The leopard (Panthera pardus) is a widespread species in India. It is protected by the national law as well as by the Convention on International Trade in Endangered Species of Wild Fauna and Flora (CITES, listed in Appendix I). However, illegal trade of leopard's bones continues to threaten its survival in the wild. Literature regarding the ossa coxarum of leopards is very rare. Hence, the present study on gross osteomorphometrical study of the ossa coxarum of 4 adult leopards was performed.
\end{abstract}

Materials and Methods: Gross morphological and morphometric study was carried out on the ossa coxarum of 4 adult leopards. Bones under study were the part of specimen collection of Centre for Wildlife Forensic and Health and also from the protected areas like Kanha tiger Reserve and Van Vihar National Park. The weight, length of os-coaxe, length of cranial, length of caudal border and length of dorsal border of os-coxae was measured and ratio of the ilium length to the ischium length was also determined.

Results: Ossa-coxarum consists of two os-coxae bones i.e. left and right. Each os-coxae consists of three large flat bones viz. ilium, ischium, and pubis. In the leopard, the conjugate diameter (At the pelvic inlet, the length between the body of the sacrum and the cranial end of the pubic symphysis) of pelvis was $7.10 \pm 0.10 \mathrm{~cm}$ and transverse diameter was $5.27 \pm 0.04 \mathrm{~cm}$. The length of cranial border, caudal border, and dorsal border was $9.10 \pm 0.15 \mathrm{~cm}, 7.35 \pm 0.13 \mathrm{~cm}$ and $5.15 \pm 0.10 \mathrm{~cm}$, respectively. The measurements were from 4 adult leopards indicating average value.

Conclusion: The gross morphological and morphometric parameter is established. This data will be useful to compare anatomical diversities among the same group.

Keywords: leopard, ossa coxarum, osteomorphometry, wildlife.

\section{I ntroduction}

The leopard is found throughout India with the exception of deserts and the Sundarban mangroves. It has a wide altitudinal range and occurs all along the Himalayas with the exception of high-altitude deserts $[1,2]$. It is the most common and widely distributed species among large carnivores in India [3]. The Leopard is listed in Appendix I of the Convention on International Trade in Endangered Species of Wild Fauna and Flora (CITES), which prohibits international commercial trade in the species (and its body parts or derivatives) between all CITES Parties. India has been a Party to CITES since 1976. Within India, the trade of live or dead leopard or its body parts and derivatives has been prohibited since the implementation of the Wildlife Protection Act (WLPA) in 1972 .

Bones of leopard are sometimes prescribed as substitutes for Tiger body parts $[4,5,6]$. The persistent belief in traditions, medicinal or folk based, that leopard

Copyright: The authors. This article is an open access article licensed under the terms of the Creative Commons Attribution License (http://creativecommons.org/licenses/by/2.0) which permits unrestricted use, distribution and reproduction in any medium, provided the work is properly cited. or other felid bones bring health or vigor to potential consumers, further increases the pressure on the life of leopards. Additionally, international demand for bones continues to encourage poaching and illegal trade, threatening the survival of the species.

The scientific information on bones of leopard is meager due to which the identification of seized bones becomes extremely difficult. Hence, the present study was carried out to illuminate the osteomorphometrical (Gross morphological and morphometric study) features of the ossa-coxarum of the leopard.

\section{Materials and Methods}

Gross morphological and morphometric study was carried out on ossa coxarum of 4 adult leopards and different morphological features and measurements were recorded. Bones under study were the part of specimen collection of Centre for Wildlife Forensic and Health and also from the protected areas like Kanha tiger Reserve and Van Vihar National Park.

The ilium was measured from the most cranial point on the iliac crest to the midpoint of the acetabulum. The ischium was measured from the midpoint of the acetabulum to the most caudal point on the ischial 


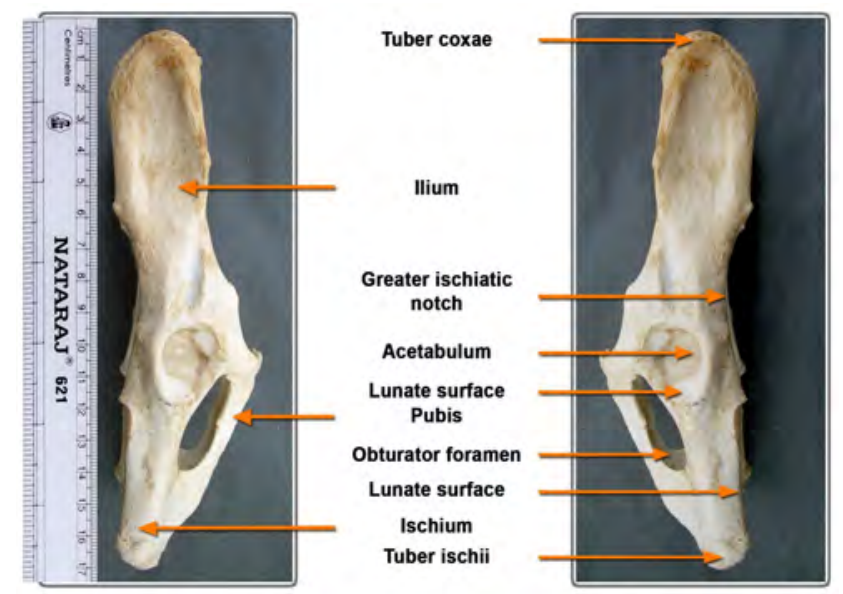

Figure-1. Lateral view of os-coxae

Table-1. Mean $\pm S$ E of different parameters of os-coxae

\begin{tabular}{ll}
\hline Parameters & Mean \pm S E \\
\hline $\begin{array}{l}\text { Weight }(\mathrm{gm}) \\
\text { Length }(\mathrm{cm})\end{array}$ & $147.02 \pm 1.69$ \\
$\begin{array}{l}\text { Length }(\mathrm{cm}) \\
\text { cranial border }\end{array}$ & $9.10 \pm 0.15 \pm 0.90 \mathrm{~cm}$ \\
caudal border & $7.35 \pm 0.13$ \\
dorsal border & $5.15 \pm 0.10$ \\
\hline
\end{tabular}

tuberosity. The two lengths were summed, and each ilium and ischium length was divided by this sum to obtain a percentage value. The ratio of the ilium length to the ischium length was also determined [7]. The data collected were analyzed for mean and standard error as per the standard procedure [8].

\section{Results}

Ossa coxarum of leopard comprised of os coxae of both sides. Each os-coxae consisted of ilium, ischium and pubis. The mean weight and mean length of the ossa coxarum bone were $147.02 \pm 1.69 \mathrm{gm}$ and $16.70 \pm 0.60 \mathrm{~cm}$. respectively (Table- 1 ).

Ilium was placed in a vertical direction parallel to each other. The lateral or gluteal surface was deeply concave while medial surface was rough and had at its lower part, elongated curved, bean shaped facet for articulation with the wings of the sacrum. The mean length and width of the ilium was $10.20 \mathrm{~cm} \pm 0.50 \mathrm{~cm}$ and $3.50 \pm 0.20 \mathrm{~cm}$. The dorsal border was thick and rounded. Lateral or cranial border was thin in its upper fourth. Caudal border was also thick and presented at its middle a projection. Greater ischiatic notch was shallow and rounded (Figure-1). Ischiatic spine was not well developed. Cranial angle was thin and sharp while the caudal angle was thick and rounded. Acetabular angle met with the ischium and pubis at the acetabulum.

Ischium was much smaller than the ilium and had twisted appearance. The mean length and width of ischium was $6.10 \pm 0.40 \mathrm{~cm}$ and $4.50 \pm 0.2 .0 \mathrm{~cm}$. The acetabular part was vertical while symphysial part was

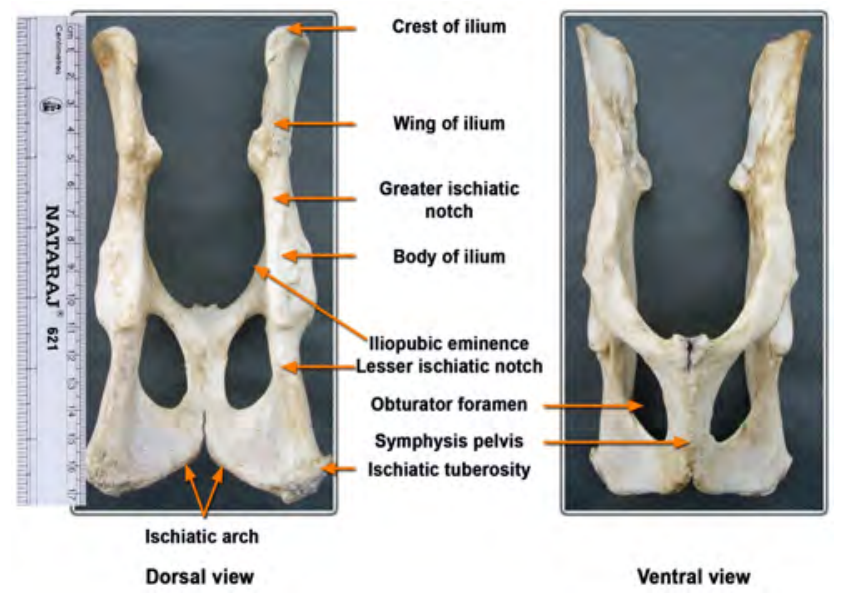

Figure-2. Ossa coxarum

Table-2. Mean $\pm S E$ of different parameters of pelvic cavity, acetabulum and obturator foramen

\begin{tabular}{ll}
\hline Parameters & Mean \pm S E \\
\hline Conjugate diameter $(\mathrm{cm})$ & $7.10 \pm 0.10$ \\
Transverse diameter $(\mathrm{cm})$ & $5.27 \pm 0.04$ \\
Pelvic symphysis $(\mathrm{cm})$ & \\
Length & $5.55 \pm 0.13$ \\
Obturator foramen $(\mathrm{cm})$ & \\
Length & $4.89 \pm 0.07$ \\
Width & $2.60 \pm 0.07$ \\
Acetabulum $(\mathrm{cm})$ & \\
Length & $3.10 \pm 0.10$ \\
Width & $2.75 \pm 0.09$ \\
Depth & $1.50 \pm 0.10$ \\
\hline
\end{tabular}

horizontal. It formed the caudal part of the floor of the pelvic cavity. Lateral border was thick, rounded and lesser ischiatic notch was not prominent. Medial border was thin, rough, met with the same border of the opposite bone, and formed the caudal part of the pelvic symphysis. Cranial border was thin, concave, and formed the caudal boundary of the obturator foramen. Caudal border was thick, rough, met with the same border of the opposite bone, and formed the v-shaped ischial arch. The caudolateral angle (tuber ischii) was very thick and rough (Figure-1). The pelvic surface was smooth and concave. The ventral surface was rough.

The caudal border of pubis was thick and formed the cranial boundary of the obturator foramen. The cranial border was thin and sharp. The medial border met with the opposite bone and formed the symphysis pubis (Figure-2). The medial angle presented a tubercle. The pelvic surface was concave whereas ventral surface was slightly convex. The mean depth of the acetabulum was $1.50 \pm 0.10 \mathrm{~cm}$. The ratio ilium to ischium length was 0.618 to 0.389 .

\section{Discussion}

The mean length of the ossa coxarum bone was $16.70 \pm 0.60 \mathrm{~cm}$. However, the same parameter of the bone was greater i.e. $24.00 \mathrm{~cm}$ in spotted deer [10]. The lateral surface/ gluteal surface of the ilium was deeply concave. The medial surface was rough and had at its lower part, elongated curved, bean shaped facet. The present observation tallied with the description of ilium of tiger [11]. The mean length of the ilium was 10.20 
$\mathrm{cm} \pm 0.50 \mathrm{~cm}$ whereas in barking deer, the length of the ilium was lesser $(9.25 \mathrm{~cm})$ than the present observation [11].

The pelvic surface of ischium was smooth and concave to accommodate the organs of the pelvic cavity. The ventral surface was rough for muscular attachment. The mean length and width $(6.10 \pm 0.45 \mathrm{~cm}$ and $4.50 \pm 0.20$ ) of ischium in the present study were lesser to the mean length and width $(7.70 \mathrm{~cm}$ and 5.35 $\mathrm{cm}$ respectively) of the ischium of the barking deer [11]. The gross morphological features of the ischium observed in the present study resembled to that of tiger [10] and $\operatorname{dog}$ [12].

The pelvic surface of pubis was concave which had increased the volume of pelvic cavity whereas ventral surface was slightly convex for attachment of muscles. The gross morphology of the pubis of leopard resembled to that of tiger [10] and dog [12]. The articular facet for articulatiuon with the wings of sacrum was bean shaped in leopard whereas the articular area was comma shaped in tiger [9]. In the leopard, the conjugate diameter of pelvis measured $7.10 \pm 0.10 \mathrm{~cm}$ and transverse diameter was $5.27 \pm 0.04$ $\mathrm{cm}$ (Table-2). The depth of the acetabulum measured in the present study was lesser to the depth of barking deer [11]. The ratio of ilium to ischium length was almost equal for leopard (Panthera pardus) compared to domestic cat (felis catus).

\section{Conclusion}

The gross morphological and morphometrical parameters were established. The information obtained by this study will be of academic importance. It is enough to affirm it because anatomical features are certain for a particular bone of a particular species

\section{Authors' contributions}

DNP and RV analyzed and interpreted the results. ABS drafted and revised the manuscript for critical scientific corrections. All authors read and approved the final manuscript.

\section{Acknowledgements}

The authors are thankful to Madhya Pradesh Forest
Department and Vice-Chancellor, Nanaji Deshmukh Veterinary Science University, Jabalpur, for providing the necessary facilities to carry out the research work. Necessary fund was provided by the Madhya Pradesh Forest department (India) through budget head number C-3 state 2(i) Establishment of Centre for Studies of Wildlife Health and Disease.

\section{Competing interests}

The authors declare that they have no competing interests.

\section{References}

1. Khan, M. A. R. (1986) The status and distribution of the cats in Bangladesh. Cats of the world: biology, conservation and management, National Wildlife Federation, Washington, D.C., p 43-49.

2. Daniel, J. C. (1996) The Leopard in India: A Natural History. Nataraj Publishers, Dehradun.

3. Johnsingh, A., Panwar, H. and Rodgers, W. (1991) Ecology and conservation of large felids in India. In N. Maruyama et al, editor, Wildlife conservation: present trends and perspectives for the 21 centuary. Proc. Intl. Symposium on Wildlife Conservation in Tsukuba and Yokohama, 21-25 August 1990., p. 160-166.

4. Pringle, C., Murgatroyd, C. and Mangal, M. (1999) CITES Compliance in Nepal. Technical report, British Embassy, Kathmandu, Nepal.

5. Sellar, J. (1999) Tiger technical missions report. Technical report, Presented at 42 nd meeting of the CITES Standing Committee, Lisbon, Portugal.

6. Nowell, K. (2000) Far from a Cure: the Tiger Trade Revisited. TRAFFIC International, Cambridge, UK.

7. Brucu, C. and Hubbard, C. (2012) Hip and Thigh Anatomy of the Clouded Leopard (Neofelis nebulosa) with Comparisons to the Domestic Cat (Felis catus). The Anatomical Record, pp 295:577-589.

8. Snedecor, C. W. and Cochran, W. G. (1994) Statistical Methods 6th edn., Oxford and IBH Publishing Co., Bombay p. 593.

9. Ranjani C.V., Sajitha, I. S., Pradeep, M. and Chungath, J.J. (2013) Gross Anatomy of the Bones of the Pelvic Limb of Spotted Deer (Axis axis). Indian Vet J. 90 (9): 45-48.

10. Pandit, R. V. (1994) Osteology of Indian tiger. Tech. Bull.No.VI., Conservator of Forest and Director, Project Tiger, Melghat, Amravati pp 46-49.

11. Kalita, A., Suri, S and Sarma, K. (2010) Anatomy of os coxae of barking deer (Muntiacus muntjal). J. of Research, SKUAST-J, Vol.9, No.-2, pp 259-263.

12. Miller M. E., Evans, H. E. and Christensen, G. C. (1979) Miller's Anatomy of the Dog. Publ., W. B. Saunders Co., Philadelphia pp 79-82. 